\title{
Cena
}

8

PERIÓDICO DO PROGRAMA DE PÓS-GRADUAÇÃO EM ARTES CÊNICAS

INSTITUTO DE ARTES | DEPARTAMENTO DE ARTE DRAMÁTICA UNIVERSIDADE FEDERAL DO RIO GRANDE DO SUL

\section{A FORMAÇÃO DO ATOR NA ESCOLA DO ATOR CÔMICO}

Ismael Scheffler ${ }^{1}$

\footnotetext{
1 Professor do Departamento de Extensão da Universidade Tecnológica Federal do Paraná, Campus Curitiba. Mestre em Teatro pela Universidade do Estado de Santa Catarina, em Florianópolis, onde realiza atualmente o doutorado.
} 
RESUMO: $O$ artigo traça um breve panorama sobre as escolas de formação de ator na cidade de Curitiba, PR, desde a Escola de Arte Dramática do SESI, criada no final dos anos 50, até o surgimento das primeiras escolas e cursos independentes, em meados dos anos 90. Após, apresenta aspectos da história da Escola do Ator Cômico, destacando a trajetória de formação de Mauro Zanatta e os primeiros anos de trabalho. A seguir, o artigo apresenta o Curso de Comédia para Atores e Não-atores, seu funcionamento e propostas pedagógicas, incluindo ao final, a transcrição de parte da entrevista concedida para a realização deste estudo, evidenciando conceitos teatrais que determinam a prática pedagógica de Zanatta junto à Escola.

PALAVRAS-CHAVE: Formação Do Ator; Pedagogia Teatral; Teatro Paranaense.

ABSTRACT: This article provides a brief overview of the actor training schools in the city of Curitiba, PR, Brazil, since SESI School of Dramatic Art, created in the late 1950's until the appearance of the first schools and independent courses in the mid 1990's. Then, it presents aspects of the history of the School of Comic Actor, highlighting Mauro Zanatta's preparation and first years of work. Next, this article describes the course of Comedy for Actors and Nonactors, its functioning and educational proposals, including the transcript of part of an interview performed for this study, showing theatrical concepts which determine Zanatta's pedagogical practice at the School.

KEYWORDS: Actor Training; Pedagogy Theatre; Theatre in Parana, Brazil.

\section{INTRODUÇÃO}

Grande parte da bibliografia sobre a história do teatro no Brasil é marcada por uma tendência de centralização do olhar sobre o eixo Rio-São Paulo $^{2}$. É certo que estes grandes que estes grandes centros urbanos foram (e são) palco de grande parte da produção teatral profissional brasileira. Rio de Janeiro e São Paulo também concentram grande parte da imprensa do país, muitos intelectuais e pesquisadores, além de diversas instituições interessadas na promoção teatral. Os cursos de graduação e pós-graduação em áreas relacionadas ao teatro há várias décadas permitem, incentivam e exigem a elaboração de pesquisas na área teatral. Todos estes fatores, entre outros, contribuíram para a existência de pesquisas e registros regionais, e até, realmente, nacionais. Mas percebe-se uma dinâmica, com algumas exceções,

\footnotetext{
${ }^{2}$ Entre as publicações que são denominadas como "teatro brasileiro" e que não refletem com abrangência ou igualdade o país pode-se citar autores importantes como: MAGALDI, Sábato. Panorama do teatro brasileiro. $3^{\mathrm{a}}$ ed. São Paulo: Global, 1997. (Publicado pela primeira vez em 1962.); PRADO, Décio de Almeida. O teatro brasileiro moderno: 1930-1980. São Paulo: Perspectiva/Edusp, 1998; CAFEZEIRO, Edwaldo, GADELHA, Carmem. História do teatro brasileiro - de Anchieta a Nelson Rodrigues. Rio de Janeiro: UFRJ / FUNARTE, 1996. Também pode-se citar obras resultantes de eventos que reúnem textos de diversos autores como: NUÑEZ, Carlinda Fragale Pate et al. O teatro através da história 2 (O Teatro Brasileiro). Rio de Janeiro: Centro Cultural Banco do Brasil / Entourage Produções Artísticas, 1994.; GARCIA, Silvana (org.). Odisséia do teatro brasileiro. São Paulo: Senac, 2002.
} 
de se contar a história do teatro nacional como a história do eixo (ou de outras localidades, quando estas se cruzam com a história do eixo). A questão é que várias publicações são intituladas como "teatro brasileiro" mas não refletem a totalidade e diversidade do país, mantendo uma imagem parcial e, por isso, limitada da produção teatral nacional.

No que tange aos estudos e pesquisas sobre história do teatro no Brasil, percebe-se também uma concentração em aspectos relacionados a questões dramatúrgicas, a encenações ou a encenadores e grupos. Falar sobre o ator brasileiro e sua formação, ainda mais sobre o ator fora do eixo, é um tema deveras importante que ainda carece de atenção e investigação.

A proposta deste artigo é apresentar informações sobre a formação do ator na cidade de Curitiba dando atenção às escolas de teatro, especialmente à Escola do Ator Cômico, dirigida por Mauro Zanatta. Esta foi uma das primeiras escolas independentes de teatro da cidade e completou, em 2009, 15 anos de trabalhos contínuos, propondo uma formação para o ator, resultante de um processo constante de reflexão e aprimoramento.

O artigo inicia traçando um breve panorama sobre as escolas de formação em teatro na cidade, desde a Escola de Arte Dramática do SESI, criada no final dos anos 50, até apontar para o surgimento das escolas particulares independentes, em meados dos anos 90. Após, apresenta aspectos da história da Escola do Ator Cômico, destacando a trajetória de formação de Mauro Zanatta e os primeiros anos de trabalho. A seguir, o artigo apresenta o Curso de Comédia para Atores e Não-atores, seu funcionamento e propostas pedagógicas, incluindo, ao final, a transcrição de parte da entrevista concedida para a realização deste estudo ${ }^{3}$.

\footnotetext{
${ }^{3}$ Para este trabalho, o autor entrevistou Mauro Zanatta, estruturando as perguntas em quatro áreas: a trajetória de formação de Mauro Zanatta; a fundação da Escola do Ator Cômico e os primeiros anos; as propostas pedagógicas da escola no presente; conceitos sobre teatro. Esta última parte é apresentada ao final deste texto transcrita integralmente. Foram realizados três encontros entre janeiro e fevereiro de 2010 que resultaram em 213 minutos de gravação.
} 


\section{ESCOLAS DE FORMAÇÃO DE ATORES EM CURITIBA - BREVE PANORAMA}

A formação de atores na cidade de Curitiba, Paraná, tem como seu primeiro registro de curso a Escola de Arte Dramática (EAD) do Serviço Social da Indústria (SESI). A EAD-SESI iniciou suas atividades em setembro de 1956 e encerrou seus trabalhos no início de 1960, sendo a primeira escola de formação em teatro do Paraná. Foi criada pela Divisão de Educação e Orientação Social do SESI em parceria com a Biblioteca Pública do Paraná, local onde as aulas foram realizadas.

A EAD ofereceu, em um primeiro momento, cursos de curta duração, elaborando na sequência um curso mais extensivo com vistas à preparação de atores. Este curso, que possuiu três turmas, foi sendo estruturado cada vez mais, aumentando-se a carga horária. Ele possuiu estruturação curricular em disciplinas (Arte de representar; História do teatro; Caracterização; Técnica de Montagem; Português; Mímica ou gesticulação; Crítica e moral) e quadro de vários docentes: Aristides Teixeira (também o diretor da escola), Armando Maranhão (que atuou também como secretário do curso); Telmo Faria; Israel Juegend, Nilo Brandão, Nicolau Ostrowski e Mbá de Ferrante.

A EAD possuía processo de seleção para o ingresso e exigia rigorosa disciplina de presença. Ela formou a geração de atores que constituíram a base do teatro profissional na cidade, podendo citar entre seus alunos: Nitis Jacon, Luciana e Aluízio Cherobim, Rubem Valduga e José Maria Santos ${ }^{4}$.

Em 1963, a Fundação Teatro Guaíra, em um movimento iniciado desde a década de 1950, com a construção do novo prédio teatral e a criação e realizações do Teatro Experimental do Guaíra, criou o Curso Permanente de Teatro (CPT), com três anos de duração, sob direção de Armando Maranhão. Maranhão, que participou do projeto da EAD-SESI, teve importante parte de sua formação no Teatro Duse, no Rio de Janeiro, com Paschoal Carlos

\footnotetext{
${ }^{4}$ Selma Suely Teixeira realizou importante e detalhada pesquisa sobre a EAD em sua dissertação de mestrado: Teatro em Curitiba na década de 50: historia e significação, defendida na UFPR, em 1992 e publicada em: TEIXEIRA, Selma Suely. Amadores em cena 2: o Teatro de Adultos e a Escola de Arte Dramática do SESI. Niterói: Bacantes, 2001.
} 
Magno $^{5}$. Em 1963, também foi criado pelo governo estadual por meio do Teatro Guaíra, o Teatro de Comédia do Paraná (TCP), estabelecendo as bases de uma produção oficial e profissional no Paraná. Parte deste projeto de incentivo à formação e realizações profissionais, corresponde à participação de atores e diretores trazidos de São Paulo para os primeiros anos do curso do CPT e encenações do TCP. Nomes como Cláudio Correia e Castro, Nicette Bruno e Paulo Goulart fazem parte deste movimento.

Em 1987, foi estabelecido convênio entre o Teatro Guaíra e a Pontifícia Universidade Católica do Paraná (PUC-PR). O CPT foi transformado em curso superior, um bacharelado com habilitação em interpretação ou direção teatral. Além dos graduados a partir de então, também se estabeleceu um processo de validação, e muitos alunos já formados no CPT realizaram mais algumas disciplinas na PUC e obtiveram reconhecimento acadêmico. Com adaptações ao perfil universitário da PUC-PR, o curso continuou com professores do CPT, permanecendo o Teatro Guaíra como centro referencial pedagógico da formação em teatro.

A partir de 1993, o curso, que por quase 30 anos esteve sob a administração do Centro Cultural Teatro Guaíra, foi transferido para a Faculdade de Artes do Paraná (FAP), deixando de pertencer ao Teatro Guaíra e à PUC-PR ${ }^{6}$. A FAP, que havia implantado em 1992 o curso de Licenciatura em Educação Artística (Habilitação em Teatro), passou a oferecer, então, três cursos na área teatral, possuindo um perfil diferenciado entre os cursos na composição do quadro docente e na utilização de espaços físicos (nos primeiros anos de incorporação dos bacharelados, as aulas ainda continuaram sendo ministradas nos estúdios e salas do barracão do Guaíra). Apenas em 1998, com a instalação da nova sede da FAP, é que a licenciatura e os bacharelados passam a coabitar. A FAP oferece atualmente os três cursos com as seguintes denominações: Bacharelado em Artes Cênicas - Habilitação em

\footnotetext{
${ }^{5}$ Maranhão também integrou, em 1952, a caravana de jovens estudantes de teatro liderados por Magno à Europa. Nesta ocasião, viajando por 10 países durante um semestre, Maranhão teve aulas com Giorgio Strehler, Jean Vilar, Federico Fellini, Luchino Visconti, Roberto Rosselini, Michelangelo Antonioni, Eduardo Di Fillipo, Diego Fabri e Lawrence Olivier.

${ }^{6} \mathrm{Um}$ processo simultâneo ocorreu com a graduação em Dança: o estabelecimento de parceria com a PUC e posterior incorporação à FAP.
} 
Interpretação, Bacharelado em Artes Cênicas - Habilitação em Direção Teatral e Licenciatura em Teatro.

Em 1980, o Colégio Estadual do Paraná (CEP) criou o Curso Técnico em Ator, em nível de $2^{\circ}$ grau, contando com a colaboração de Armando Maranhão. Este curso escolar profissionalizante foi responsável pela formação de grande número de atores no Paraná. Existiram durante a década de 1980, dois cursos de teatro com habilitações distintas: Ator e Técnico de Teatro, com duração de quatro anos cada. Com o advento da Lei 9.394 de 1996, que trouxe uma nova configuração para a Educação Profissional e as políticas adotadas a seguir, as modificações impostas levaram ao fechamento dos cursos. Em 2009, após a retomada do ensino profissionalizante no Ensino Médio, o CEP retomou a formação de atores com o Curso Técnico em Arte Dramática - habilitação em Ator Cênico, um curso subsequente de nível médio, com três semestres de duração.

De 1998 a 2008, a Escola Técnica da Universidade Federal do Paraná (UFPR) ofereceu o Curso Técnico em Artes Cênicas - Ator, como curso técnico pós-médio, com dois anos de duração. Em 2009, este curso foi transformado no Curso Superior de Tecnologia em Produção Cênica - Formação de Atores, passando a compor o painel de cursos superiores da UFPR. À frente desta empreitada, encontra-se, entre outros, o diretor teatral argentino Hugo Mengarelli.

Recentemente, em 2010, a PUC-PR iniciou o Curso de Bacharelado em Artes Cênicas.

Ao se falar sobre a formação do ator em Curitiba, é preciso ainda mencionar as escolas independentes e particulares de teatro que começaram a surgir a partir de meados dos anos 90, que marcam fortemente o panorama teatral da cidade ${ }^{7}$. Entre 1994 e 1995, surgem com a denominação de escolas, ou na forma de cursos regulares que conduzem à formação de escola de

\footnotetext{
7 Outro campo de formação escolar que poderia ser apontado seriam os trabalhos realizados em instituições de ensino regular, públicas ou privadas, onde o teatro assume característica de atividade extracurricular ou extensão, como o caso da Universidade Tecnológica Federal do Paraná, que desde 1972 mantém atividades teatrais, como grupo de teatro e oficinas. Embora o objetivo deste tipo de atividade não seja de formar atores para a carreira profissional e sim oferecer o teatro como campo para 0 desenvolvimento, este fator não impede que diversos alunos se encaminhem para o teatro profissional posteriormente, tendo esta atividade como base de sua formação inicial. No entanto, este campo não será abordado por este estudo.
} 
teatro, cinco instituições: a Escola do Ator Cômico, em 1994, o Cena Hum Academia de Artes Cênicas ${ }^{8}$, o Pé no Palco ${ }^{9}$, a escola dos Satyros ${ }^{10}$ e o Núcleo de Profissionalização Teatral do Teatro Lala Schneider ${ }^{11}$, estes em 1995.

$\mathrm{Na}$ sucessão dos anos, da década de 90 até o presente, diversas escolas de teatro particulares e cursos independentes foram criados e são ministrados em Curitiba, oferecendo formação atoral. Estes cursos possuem modelos diferentes de ensino, com cargas horárias e durações variadas, perfis docentes, metodologias e objetivos específicos. Entre estas escolas pode-se citar, por exemplo, entre outras, o Liceu Marina Machado, o Espaço Cênico (antigo ACT - Atelier de Criação Teatral), o Teatro Odelair Rodrigues, a Cia. do Abração e o Teatro Cultura.

\section{A CRIAÇÃO DA ESCOLA DO ATOR CÔMICO}

A Escola do Ator Cômico foi criada em 1994 por Mauro Zanatta e Pita Belli (Patrícia de Borba). A escola se destaca no panorama de Curitiba não apenas por ser a primeira escola particular independente de teatro da cidade, mas por sua proposta diferenciada. Enquanto outros cursos se propõem à formação de atores e oferecem cursos regulares com carga horária distribuída em vários semestres, a Escola do Ator Cômico oferece atualmente um curso único de média duração e a trabalhar o ator por meio da comédia.

\footnotetext{
${ }^{8}$ O Cena Hum - Academia de Artes Cênicas foi fundada por George Sada, inaugurando a escola com uma proposta curricular envolvendo diferentes professores. Sada foi aluno da PUC-PR e em seguida professor da FAP, deixando a faculdade para se dedicar ao Cena Hum.

${ }^{9}$ O Pé no Palco, dirigido por Fátima Ortiz, iniciou cursos de teatro no Teatro Novelas Curitibanas em parceira com a Fundação Cultural de Curitiba, em 1995. Em 1998, os cursos livres de teatro passaram a acontecer no Museu Metropolitano de Arte do Portão e, em 2002, o Pé no Palco se instalou em sede própria no bairro Rebouças. Ortiz foi aluna do CPT.

10 A Companhia de Teatro Os Satyros, tendo à frente Ivam Cabral e Rodolfo García Vázquez, que retornou de São Paulo a Curitiba em 1994, criou em 1995 as Oficinas Livres de Interpretação Teatral, inaugurando uma escola em sua sede. A companhia retornou novamente para São Paulo em 2000 e os cursos foram realizados até 2005.

${ }^{11}$ Em 1994, João Luiz Fiani fundou o Teatro Lala Schneider e a Companhia Máscaras de Teatro, criando em 1995 o Núcleo de Profissionalização Profissional, com uma proposta de curso curricular com diversos professores. Fiani foi aluno do CPT.
} 
A proposta atual difere da proposta inicial da escola. Em sua fundação a proposta era a de oferecer cursos para atores profissionais, sendo um espaço para o aprendizado de linguagens técnicas específicas do teatro como a commedia dell'arte, o clown, a máscara, a improvisação. Com o passar dos anos esta proposta mudou e a escola passou a oferecer um curso único, o Curso de Comédia para Atores e Não-Atores.

A Escola do Ator Cômico se funde com a figura do ator e professor Mauro Zanatta. Seu perfil e programa se espelham na trajetória deste fundador e único professor no momento.

\section{1 - A FORMAÇÃO EM TEATRO DE MAURO ZANATTA}

Mauro Zanatta nasceu na cidade de Concórdia, interior de Santa Catarina, em 1961. Sua aproximação ao teatro aconteceu em 1982, quando cursava Engenharia Mecânica, na Universidade Federal de Santa Catarina, em Florianópolis. Sentindo necessidade de realizar uma atividade diferente da atividade acadêmica regular, descobriu um curso de mímica no qual se inscreveu sem grandes expectativas para com a arte teatral. O impacto do primeiro dia do curso foi definitivo para o abandono da graduação em engenharia e a dedicação à carreira de mímico. A formação - e primeira referência de teatro - se deu por meio de um curso de três meses com o mímico argentino Daniel Berbédes, com quem, na sequência, também desenvolveu alguns trabalhos.

A mímica se tornou então a linguagem por meio da qual desenvolveu seu trabalho "de cara branca e silencioso", recebendo o Prêmio Valdir sequência, como Ator Revelação, em Florianópolis, ainda em 1983.

Envolvido com movimentos sociais, acreditava no teatro como arte popular e preferia o espaço das ruas, festas e bares como local para se apresentar ao invés de palcos de salas de teatro. No início desenvolveu parceria com Marcos Cruz, passando algum tempo depois a trabalhar sozinho. 
Após três anos trabalhando com essa base de formação, sentiu certo esgotamento. Nesta época, realizou uma viagem a Olinda, Pernambuco, onde tomou contato com o teatro de bonecos. Permaneceu por seis meses residindo na cidade e aproximou-se de Ceça Acioli e Afonso Miguel (Fofão), com quem realizou alguns trabalhos articulando teatro de bonecos e mímica. Mestre Saúba, bonequeiro, é apontado por Zanatta como uma referência marcante da época e de sua aproximação com o teatro de bonecos, pela capacidade que possuía de jogar e improvisar com os elementos do ambiente.

Nesta mesma época, participou de um curso no Rio de Janeiro, ministrado pela psicóloga Anne Lapierre sobre Psicomotricidade Relacional. As possibilidades do desenvolvimento de relacionamentos por meio da brincadeira marcaram Zanatta ao reconhecer, entre outros aspectos, o despertar do prazer pela ludicidade e este meio como forma de desenvolver relacionamentos.

Depois de receber, em Olinda, uma crítica contundente a seu trabalho, interrompeu sua atuação em teatro e regressou a Santa Catarina, trabalhando por um ano em um sítio com horticultura.

Influenciado pela tendência de muitos jovens da década de 1980 de trabalhar na Europa, em 1987 se mudou para a Inglaterra e passou a trabalhar como garçom. Após um ano em Londres, tomou conhecimento da Desmond Jones School of Mime and Phisical Theatre. Estando já há dois anos longe do teatro, Zanatta o retomou acompanhando as aulas de Desmond Jones, cursando diversas disciplinas, aprendendo e aprimorando diversas técnicas como a mímica, o clown, a confecção e utilização de máscaras. Zanatta permaneceu no curso por um ano, sendo convidado na sequência para ser professor assistente de Jones.

Depois de seis meses como professor assistente, seguiu para a Itália para participar de um curso de commedia dell'arte com Antonio Fava, na Scuola Internazionale dell'Atore Cómico, na cidade de Reggio Emilia, onde permaneceu por um mês.

Retornando a Londres, foi convidado para trabalhar na Arts Educational Schools London, entre 1990 e 1991, como professor de mímica, clown e commedia dell'arte. 
Juntamente com alguns amigos, Zanatta promoveu a ida para Londres do diretor francês Philippe Hottier, ex-membro da companhia Théâtre du Soleil, para ministrar uma oficina de uma semana sobre clown. A oficina dirigida por Hottier, segundo Mauro Zannatta, foi marcada pela exploração de arquétipos, expansão das sensações, resgate da memória do ator e o encontro com a dificuldade, o não-personagem, o trabalho sobre a respiração como processo de desenvolvimento, o relacionamento com a plateia e o desenvolvimento de reflexões sobre o trabalho do ator como artista inserido em sua época. Sem trabalhar com a forma, propôs um trabalho de clown a partir do universo do ator. Esta experiência aproximou Zanatta de outros referenciais técnicos e artísticos, sendo uma experiência de profunda influência em sua carreira.

Em 1992, Mauro Zanatta regressou ao Brasil e se instalou em Curitiba, Paraná. Sem ter contatos na área teatral, passou o primeiro ano dando aulas de inglês. No ano seguinte, promoveu uma oficina na Casa do Estudante Universitário (CEU) e passou a estabelecer contatos. Por ocasião do Festival de Teatro de Curitiba, em 1993, realizou outra oficina e ampliou suas relações com o meio teatral. Na sequencia, conheceu Pita Belli e Cleide Piaseki, atrizes que trabalhavam juntas como uma dupla cômica.

\section{2 - A PARCERIA COM PITA BELLI E OS PRIMEIROS ANOS DA ESCOLA}

Mauro Zanatta e Pita Belli decidiram reunir suas experiências e conhecimento sobre o teatro e a comédia e resolvem criar juntos uma escola. Pita Belli era atriz profissional há alguns anos e havia acabado de se formar no curso superior em Direção Teatral pela PUC-PR. Encontrando afinidades não apenas na área da comédia, mas também em propostas sobre o ensino do teatro, visualizaram possibilidades de desenvolver um trabalho complementar.

A Escola do Ator Cômico (nome proposto por Zanatta a partir da Scuola Internazionale dell'Atore Cómico) foi inicialmente estruturada em oficinas, em um formato de escola dividida em módulos, de forma similar ao modelo francês 
da École Philippe Gaulier, onde o aluno se inscreve nas oficinas que the interessam ${ }^{12}$.

Nos dois primeiros anos, a Escola do Ator Cômico oferecia oito oficinas independentes em um período de quatro meses ${ }^{13}$. Cada oficina possuía 24 horas e era desenvolvida em duas semanas de aula. O aluno podia optar por todas oficinas ou somente por aquelas que mais Ihe interessassem. As oficinas eram oferecidas na seguinte sequência:

- Oficina 1 - Introdução ao teatro cômico ("Uma visão histórica do universo cômico através da prática das técnicas que permeiam o seu surgimento"), ministrada por Zanatta e Belli;

. Oficina 2 - Clown ("Um jeito muito particular de relacionamento teatral onde o ridículo é trazido à tona para a formação do elemento cômico, num estudo sobre o universo do clown, seus truques, fantasias e relação ator/platéia."), ministrada por Zanatta;

. Oficina 3 - Improvisação ("Brincando com as técnicas de improvisação de Keith Johnstone em busca da espontaneidade e imaginação, chegamos ao fascinante estilo do teatro do improviso."), ministrada por Zanatta;

. Oficina 4 - Mímica contemporânea ("Uma análise técnica e prática do movimento enfocando a participação da mímica na construção da personagem, gesto, improvisação e linguagem corporal."), ministrada por Zanatta;

- Oficina 5 - O gesto e o texto ("Uma abordagem do gesto enquanto reforço do texto e/ou contradição da idéia, contextualizado no todo da linguagem corporal."), ministrado por Belli;

\footnotetext{
${ }^{12}$ Na École Philippe Gaulier são oferecidos os seguintes cursos: O Jogo; Máscara Neutra; Tragédia Grega; Bufão; Melodrama; Máscaras; Personagens; Shakespeare e Tchecov; Clowns; Escrevendo e Dirigindo um Espetáculo.

${ }^{13}$ As informações sobre as oficinas foram obtidas por meio dos folders de divulgação utilizados na época.
} 
- Oficina 6 - Máscaras ("Construção e manipulação de vários estilos de máscaras: máscara 'neutra', 'larval' e 'meia-máscara'. A função da máscara no teatro e na preparação do ator.");

- Oficina 7 - Análise e interpretação do texto cômico ("Um estudo da estrutura do texto cômico com suas variantes e incorporação da técnica que mantém essa mesma estrutura."), ministrada por Belli;

- Oficina 8 - Commedia dell'arte ("A commedia dell'arte continua influenciando o teatro contemporâneo depois de quatro séculos de seu nascimento. Uma divertida e necessária visão sobre este estilo nascido no século XVI."), ministrada por Zanatta.

Em 1996, uma nova estrutura foi dada, aumentando-se a carga horária de algumas oficinas e requerendo-se oficinas como pré-requisitos de outras:

. Oficina 1 - Introdução ao teatro cômico, com 24 horas;

. Oficina 2 - Clown (exercício da criação), com 36 horas;

. Oficina 3 - Improvisação, com 36 horas;

- Oficina 4 - Mímica contemporânea, com 36 horas, sendo pré-requisito a partir da $4^{\underline{a}}$ oficina, uma das oficinas anteriores;

. Oficina 5 - Análise e interpretação de texto, com 36 horas, sendo prérequisito para oficina 5 , participar da oficina 4 ;

- Oficina 6 - A comédia no palco, com 24 horas, sendo pré-requisito para a oficina 6 , participar das oficinas 4 e 5 .

Em 1997, algumas oficinas foram realizadas intercaladas em dias da semana. Foram oferecidas da seguinte forma: Introdução ao teatro cômico; Clown; Improvisação, às segundas e quintas-feiras com Mímica contemporânea, às terças e quartas-feiras; $O$ gesto e o texto, às segundas e quintas-feiras com Clown em cena, às terças e quartas-feiras; Montagem de espetáculo clown. 
Cada professor desenvolvia suas oficinas a partir de suas experiências e da formação da qual era oriundo. Pita Belli articulava questões relativas ao texto, ao gesto na relação com o texto, permeados com aspectos do cômico e da improvisação vivenciados no palco.

Pita Beli permaneceu na escola até $1998^{14}$. A partir de então, a condução da Escola do Ator Cômico ficou sob a direção de Zanatta que manteve um mesmo perfil de cursos. Zanatta ainda desenvolveu alguns projetos em parceria com outros profissionais, como a terapeuta corporal Arnand Djarna, em 1999, o ator Richard Rebelo e o músico Nélio Sprea, em 2002. Estas experiências trouxeram contribuições, mas levaram Zanatta a perceber que a proposta do curso que dirigia tinha características que eram muito próprias de uma elaboração que vinha realizando ao longo dos anos. A partir de 2003, decidiu assumir o trabalho sozinho, sem incorporar outros ministrantes para as aulas.

A proposta inicial era de ser uma escola para atores profissionais, como um espaço de "reciclagem". No entanto, o número de atores profissionais que procurava a escola era pequeno, ao passo que o número de pessoas que buscavam informações para cursos de iniciação em teatro, grande. Aos poucos, iniciantes foram sendo admitidos e inseridos nas mesmas turmas de oficinas com atores profissionais. As oficinas e técnicas oferecidas eram pouco dominadas pelos profissionais, o que se configurava como um campo de desenvolvimento de aprendizagem de linguagens novas a todos. Para uns, possuía um caráter de uma formação continuada e, para outros, a aprendizagem do teatro como primeira expressão. Percebendo que muitos atores profissionais provinham de uma formação que compreendia o teatro com um enfoque mais centrado no texto e na marcação cênica e careciam do

\footnotetext{
${ }^{14}$ Tendo começado a lecionar na Universidade Regional de Blumenau (FURB), em Blumenau, SC, Pita Belli foi ocupando cada vez mais espaço profissional dentro da universidade. Primeiramente apenas lecionava, assumindo depois também a direção do Grupo Teatral Phoenix, atividade de extensão da universidade, e posteriormente a coordenação do Festival Internacional de Teatro Universitário de Blumenau. Encontrando cada vez mais dificuldades de manter as duas atividades, decidiu dedicar-se à carreira universitária. Posteriormente Pita Belli assumiu também a editoração da Revista $O$ Teatro Transcende, a coordenação do curso de Especialização Lato Sensu em Encenação Teatral e continuou investindo em sua formação na realização do curso de mestrado junto ao Programa de Pós-Graduação em Teatro (PPGT) da Universidade do Estado de Santa Catarina (UDESC), onde desenvolveu a pesquisa: A utilização dos Exercícios de Status de Keith Johnston no treinamento do ator através das técnicas de clown. Atualmente realiza seu doutorado na mesma instituição, sobre As Implicações da Improvisação segundo Jonston, com pesquisa ainda em desenvolvimento.
} 
desenvolvimento do jogo e da improvisação, reunir atores profissionais e iniciantes foi considerado muito positivo por possibilitar a descoberta destes aspectos a todos. A presença de atores profissionais caracteriza a escola até os dias de hoje.

A escola, que nos primeiros anos não possuía sede própria, oferecia a cada ano seus cursos em diferentes espaços e instituições, em bairros diferentes da cidade. Embora já se denominasse como uma escola desde o primeiro ano, foi somente a partir do ano 2000, após passar por cinco endereços diferentes - abrigada por instituições de diferentes perfis -, que a escola se estabeleceu em uma sede própria, localizada à rua Lamenha Lins, 1.429, no bairro Rebouças, onde tem sua sede até o momento ${ }^{15}$. Segundo Zanatta, a definição do espaço físico deveria ser decorrente de uma estabilidade da escola, filosófica e existencial:

\begin{abstract}
"no momento em que a escola passasse a existir realmente é que eu me preocuparia com um espaço físico. Eu não partiria de um espaço físico, de aluguel de um espaço grande, de um investimento, sem ter certeza de que seria um investimento real. A idéia era: a partir do momento que eu perceber que o investimento é real, que a escola tem uma caminhada própria, aí sim o espaço físico vai começar a abraçar a escola." (ZANATTA, 2010).
\end{abstract}

A escola também abriga a Companhia do Ator Cômico e a Estufa Cultural. A companhia integra um elenco estável, todos ex-alunos da escola. A Estufa, também integrando ex-alunos da escola, funciona por meio de projetos de produção independente definidos em objetivos e duração, embora permita com que seus integrantes participem de mais projetos sucessivamente.

\footnotetext{
15 A Escola utilizou de 2000 a 2008, a estrutura de um sobrado construído inicialmente para ser residência, adaptado para servir de sede. Em 2009, foi finalizado um prédio próprio, no mesmo terreno, atrás do sobrado. A sede da escola possui uma ampla sala de múltiplos usos, uma black box, utilizada para as aulas e ensaios que possui piso de linóleo e arquibancadas móveis, permitindo reconfigurações da utilização da sala. A sala toda possui estrutura de urdimento para equipamento de iluminação, cenografia e adaptações de vestimenta de palco, e uma janela de visualização para a cabine técnica. A sala foi projetada para receber platéias de até 40 pessoas e banheiros com acesso externo. Possui também dois camarins, depósito de materiais cênicos e guarda-roupa, secretaria, uma pequena biblioteca e uma sala múltipla utilizada para o café.
} 


\section{O CURSO DE COMÉDIA PARA ATORES E NÃO-ATORES}

\subsection{REINVENTANDO A ESCOLA - AMPLIANDO FUNDAMENTOS}

A escola passou a oferecer desde 2003 um único curso, o Curso de Comédia para Atores e Não-atores, com 30 vagas e idade mínima de 18 anos. Entre 2003 e 2009, o curso possuía a duração de 16 semanas, com três encontros semanais, de segunda a quarta-feira, das 19h às 22h. Até 2008, manteve a característica de oferecer apenas uma vez ao ano o curso, no primeiro semestre. A partir de 2010, esta estrutura foi tomada de forma mais flexível, e cursos também serão oferecidos com menos ou mais semanas de duração.

A articulação entre o trabalho de ator e o trabalho como professor influencia na oferta de cursos, tanto no período anual em que ocorre quanto em sua duração. Transitar entre atuar e ensinar é considerado fundamental por Zanatta (2010):

\footnotetext{
"Eu me vejo como foco. Meu trabalho de ator também é foco. Se eu parar de atuar, eu perco muito no ensino. Então eu fico transitando entre atuar e ensinar. É a maturidade de meu ator que sempre vai trazer material, vai me dar sempre informações para estar estruturando e reestruturando o curso, e vice-versa. A medida de minha proposta está baseada em minha própria experiência como ator: o que me angustia no palco, o que me traz prazer, o que me impede de jogar. As coisas vão circulando entre 0 ator e 0 professor."
}

A influência europeia marcou os primeiros anos da escola pelo perfil dos cursos, técnicas e modelo de estruturação em disciplinas isoladas. Com o passar dos anos, no entanto, Zanatta foi elaborando uma proposta mais pessoal, até a elaboração de um curso único. 
O clown, a commedia dell'arte, a mímica e a máscara passaram a ser considerados cada vez menos como elementos centrais, constituindo-se como instrumentos para um trabalho sobre o ator. Se, por um lado, a commedia dell'arte trazia aspectos novos para o jogo do ator, por outro, Zanatta identificava que as formas acabavam condicionando e prendendo muitos atores em fórmulas esvaziadas, em estereótipos. Passou, então, a questionar o repasse da técnica, pois acreditava que muitas pessoas assimilam a técnica sem compreender a origem, a motivação de seu nascimento, e se tornavam apenas reprodutores das formas. Zanatta passou a se preocupar com alguns elementos que dificultavam o aprendizado técnico: o que impede o ator de jogar, de brincar, de criar, de ter processos contínuos de criação, de ter espontaneidade.

Visando libertar 0 ator de si mesmo e dos elementos que 0 aprisionavam, a escola foi sendo reinventada. Zanatta passou a valorizar mais a capacidade de jogar e improvisar, incorporando princípios experimentados no trabalho com Hottier. Para Zanatta, a improvisação

\footnotetext{
"é o fundamental, a base. A pessoa que sabe improvisar vai emprestar para o clown, para a commedia dell'arte e outras técnicas, uma fundamentação muito importante, pois conseguirá chegar a uma espontaneidade dentro de um tipo, construir um tipo e dar vida aos arquétipos sem estar aprisionado neles" (ZANATTA, 2010).
}

Aos poucos passou a diminuir o ensino de formas técnicas e passou a destinar maior atenção ao jogo e a improvisação. Zanatta foi percebendo que os atores muitas vezes transformavam as técnicas da commedia dell'arte e do clown em truques, engessando formas, como um acervo de clichês que não permitia uma criação própria para aquele tipo. "Era um vestir e não um trocar e criar um novo caminho de comunicação" (ZANATTA, 2010). Estas linguagens acabavam sendo "bengalas", pois o ator não parecia encontrar a segurança para brincar com aqueles elementos, principalmente com a commedia. 
O clown foi uma das linguagens que primeiramente teve sua presença diminuída nos cursos, pois Zanatta percebeu que existia uma expectativa formalista que condicionava e acabava limitando o desenvolvimento do jogo.

O jogo tornou-se a base do trabalho: "sem o jogo, a cena não sobrevive", e constrói cada vez mais sua proposta nesta convicção:

"Eu preparo as pessoas para elas fazerem o exercício técnicofísico, de teatro físico, de mímica, para elas poderem aproveitar estas técnicas. Eu não me interesso mais pela técnica pura. O que quero desenvolver é a liberdade para que a pessoa perceba a técnica e sua maneira de aproximação dela - um ator que tenha contato consigo mesmo, com seu material pessoal." (ZANATTA, 2010)

Reconhecendo o jogo e a improvisação como fundamentais a todas as linguagens e técnicas, passou a valorizar cada vez mais a capacidade do ator estar presente o tempo inteiro, não apenas atuando ou representando, mas estar sensível a si, ao meio e ao outro (ator e público), aproveitando os elementos potenciais presentes do momento.

Neste processo, Zanatta reformulou a proposta pedagógica da escola e passou a oferecer um curso único: o Curso de Comédia para Atores e Nãoatores - que sintetizava sua maneira de compreender a formação do ator. Zanatta passou a valorizar mais outros elementos de sua trajetória como a influência da oficina com Philippe Hottier e aspectos da Psicomotricidade Relacional. Para Zanatta estas duas referências possuem aspectos correlacionados de valorização do lúdico e do ser humano.

Embora a proposta atual não seja de ser um curso terapêutico, Zanatta reconhece que há aspectos terapêuticos em seu processo no que se refere às limitações impostas ao ator pelas experiências e tragédias pessoais:

"as tragédias individuais alojadas no corpo são como um freio-demão puxado que impedem o ator de trabalhar. Ao reconhecer suas neuroses, suas raivas, dores e mágoas, 0 ator permite 0 
desenvolvimento de um novo parâmetro de relacionamento com o mundo, amplia sua capacidade de jogar com a comédia. Se a comédia é uma releitura da tragédia, como de fato é a comédia, que consegue mostrar uma situação trágica a partir de outro ponto de vista, por que não provocar isto nas pessoas? Isso faz com que elas possam descobrir esta tragédia e fazer uma leitura e começar a brincar e a partir daí desencadear seu processo como ator." (ZANATTA, 2010)

Na sequência deste processo de reelaboração de si e de sua proposta pedagógica, Zanatta tem se dedicado à pesquisa na área da psicologia reichiana, participando de um curso de formação, buscando compreender as relações entre o corpo e a mente.

Zanatta define o trabalho da escola afirmando que:

"A Escola do Ator Cômico é um mecanismo em construção. É muito diferente da escola no começo; antes ela era fechada, ela tinha um processo fechado. Hoje ela é um instrumento de conhecimento. Ela é um local onde a gente retorna as bases por meio de técnicas de comédia. Por meio das técnicas de comédia você retorna as suas bases para descobrir novas relações com o mundo. É um local onde a gente chafurda no nosso próprio ser para descobrir como ampliar as nossas relações e conseqüentemente ampliar o nosso processo artístico." (ZANATTA, 2010)

\subsection{O FUNCIONAMENTO DO CURSO}

Mauro Zanatta concebe o curso com flexibilidade e adaptabilidade ao perfil de cada turma. O curso não possui uma sequência rígida ou fixada de exercícios. Ele possui um programa que guia o desenvolvimento das atividades e um leque de exercícios e jogos a serem propostos. 
"A escola se define como um local onde nenhum curso é igual ao outro. A cada turma, e a cada ano que passa, o encontro entre alunos e professor é uma nova jornada de aprendizado, que flui de ambos os lados." (ZANATTA, 2010)

Podem ser apontadas três fases ao longo do curso: o resgate da expressão pessoal, a improvisação e o palco limpo. O objetivo da primeira etapa é resgatar a brincadeira e a espontaneidade para entrar nos processos de improvisação e chegar à percepção do jogo. É preciso, então, reconhecer e se abrir à brincadeira. Esta fase pode durar cerca de um mês, podendo ser mais ou menos, dependendo da necessidade do grupo. As qualidades pessoais são valorizadas na mesma proporção que suas dificuldades, que são valorizadas como parte do repertório do aluno, "pois é o exercício diário com estas dificuldades que deve gerar o seu material criativo" (ZANATTA, 2010). Segundo Zanatta, as brincadeiras e os jogos propiciam a segurança necessária à exposição e reconhecimento de sua estrutura pessoal e social. Visando a disponibilização ao jogo, são trabalhadas questões como a exposição, o risco, a percepção do externo e a espontaneidade.

"O adulto não brinca mais. Ele finge de brincar. Eu proponho brincadeiras que resgatem o adulto. Vou identificando pras pessoas elementos que são muito claros: o relacionamento entre as pessoas, o prazer, a necessidade do risco e o medo de arriscar, o aprisionamento do acerto, o não se permitir brincar por brincar, o errar e o consertar. Essa primeira etapa corresponde a um resgate da espontaneidade, do relacionamento espontâneo, de prazer, de olhar pras pessoas sem um interesse óbvio, de abrir seu olhar para fora, de se posicionar e contar um pouco de você: de você - não do ator. É trabalhar a 'pessoa' e não o 'ator'. Principalmente nesta primeira etapa o 'ator' atrapalha mais do que ajuda. Então vou tentando limpar esses vícios de representação, esses vícios de não estar presente, de não conseguir parar, ficar em pé no mesmo lugar, olhar pras pessoas e contar alguma coisa, viver emoções. Coisas muito básicas de comunicação. De estar presente, de trabalhar no tempo presente. Se você está na frente das pessoas e 
está sofrendo com esta situação de não conseguir criar alguma coisa, você precisa se conectar com este sofrimento, com essa incapacidade criativa e conseguir expor isso de alguma maneira, seja contando, brigando, se depreciando. É o momento de fazer com que a pessoa entre em contato com sua incapacidade, saindo do estado de "eu necessito ter sucesso, eu necessito ser bom, eu preciso ser o maior, eu preciso ser grande". É trazer a pessoa para base dela de novo: 'você é uma pessoa normal'." (ZANATTA, 2010)

A partir de então, na segunda etapa, passam a ser desenvolvidos processos de improvisação com jogos que trabalham na definição de algumas técnicas que promovem a improvisação. São trabalhados jogos de improvisação que estabelecem as relações entre ator/ator e ator/plateia, para desenvolver tecnicamente a prontidão e a presença: estar com alguém em cena, estar ouvindo, o estado de concentração - que não é isolada, mas em movimento, conectado com o exterior. A pessoa passa a usar mais sua base, estando mais presente, sem precisar projetar uma "super criação", inventando sempre coisas maravilhosas. Já foi limpo do excesso de originalidade e da busca pela "grande criação", e se conscientizou sobre o risco da dinâmica viciada de negação da proposta vinda do colega, e se disponibiliza ao outro, se disponibiliza a ouvir:

"Normalmente a pessoa entra em cena projetando idéias. No entanto, é possível que esta projeção seja diminuída e a pessoa seja mais flexível às idéias do outro: eu não me fecho em mim, mas me concentro no lugar onde estou, no jogo que está se desenvolvendo e nos sinais que estão acontecendo em volta de mim (como ruídos) ou interno, em mim (algo emotivo, ou uma memória acordada no processo). É um estado de pensar-e-fazer, um estado presente e próximo (menos futuro e menos passado)." (ZANATTA, 2010)

Um terceiro estágio do curso é chamado por Zanatta de palco limpo. Neste trabalho, o ator é desprovido de qualquer subterfúgio. Ele é desafiado a 
criar sem o uso de objetos em cena, sem recorrer à mímica para criar ilusão. É o ator e a dificuldade dele naquele momento.

Ao ator é proposto estar em cena despojado de qualquer técnica ou de qualquer condução, produzindo apenas com o material que tem: quem ele é, quais são os primeiros contatos que recebe na cena, os conflitos com o colega, os conflitos pessoais - é o ator produzindo seu material a partir de improvisação. Sem canais para escapar daquele momento, resta ao ator o confronto do momento presente.

A proposta é lançada a partir das perguntas: "quem sou?", "o que faço?". Zanatta afirma que num primeiro momento as pessoas começam apresentando seus clichês, sobre seu próprio material consciente. Começam a apresentar esse "sou" de uma maneira muito estabelecida. Afirma também que com o decorrer do tempo elas começam a perceber de que esse "sou" depende de cada momento, do que se faz no momento também. A cada improvisação a pessoa é alguém novo, alguma outra coisa, algum outro ser, e faz outra atividade, e o ator produz outro material. Então acaba se estabelecendo um jogo de momento. Aí começa a haver um processo de flexibilização, de mergulho no seu material inconsciente, de subjetividade.

"Eu tento fazer com que o ator identifique onde ele está fugindo dele mesmo, onde está se escondendo. Por isso é o palco limpo. Existe um processo meu de relacionamento com o ator, de perceber onde ele está apenas representando - e o ator não se apresenta, ele não entra em contato com ele mesmo. Em alguns casos, as tentativas de comunicação com 0 ator demoram a acontecer, pois 0 ator acaba envolvido numa nuvem, num estado que ele mal percebe a platéia a sua frente, o colega ao seu lado. O palco limpo é fazer com que 0 ator volte-se para si mesmo, volte-se para suas dificuldades e não perceba seus clichês. Por que a partir daí ele vai se construindo, construindo sua comunicação." (ZANATTA, 2010)

São estabelecidos alguns jogos como o não uso da palavra, usando apenas sons, e outro como trabalhar com o macaco, com a energia do macaco, 
de desenvolver um trabalho primário de respiração, de postura corporal, de quebrar a verticalidade das pessoas, de fazer com que elas se envolvam mais com o movimento corporal e usar este elemento do macaco no relacionamento, dentro de exercícios. Sempre com estas duas perguntas, "quem sou" e "o que faço". Segundo Zanatta, o macaco deixa o ator mais primário, menos racional e o jogo cômico mais aparente. Assim podem ser trabalhadas questões como a triangulação, o tempo teatral e o jogo cômico.

Cada encontro de aula tem três horas de duração e possui uma dinâmica interna estruturada em momentos com objetivos distintos. Primeiramente, Zanatta dedica cerca de 30 minutos para um aquecimento físico-emocional, destinado ao estabelecimento de um estado de concentração e alerta. Neste momento, o professor também realiza um levantamento do grau de excitação e busca excitar os alunos: tirar de um estado racional para entrarem um estado mais orgânico, onde a racionalidade baixa e o corpo começa a entrar no jogo, com olhar e audição mais atentos. O momento também se destina ao estabelecimento de uma percepção do aluno sobre si próprio e sobre as pessoas que estão ali, servindo também de estímulo à interação. O trabalho envolve respiração, relaxamento, jogos com objetos, dança, música e brincadeiras cotidianas.

O segundo momento, com cerca de sessenta minutos, envolve brincadeiras ou exercícios de improvisação com o grupo todo, trabalhando-se frequentemente em duplas, desenvolvendo a escuta, a cumplicidade e a relação.

O terceiro momento é um trabalho de palco e de relação com a plateia, individual ou em dupla. Tem de sessenta a noventa minutos. É a "saída da cortina", no qual o aluno trabalha com o espaço vazio, criando com o que existe no momento: o que estou vivendo, as coisas que estão emergindo em mim, o que o colega que está comigo propõe.

A aula também é marcada por dois outros momentos: o momento do "batepapo" e o do café. Estes dois momentos aparecem como característica marcante do curso, pois a elas é destinado um espaço elaborado diariamente com tempo significativo. 
O momento do "bate-papo" não acontece em uma parte fixa da aula, transita dentro da programação. É destinada uma média de 20 a 30 minutos. $\mathrm{O}$ curso se caracteriza prioritariamente pela prática de jogos, exercícios e improvisações. Neste sentido, este espaço caracteriza-se por uma mudança na dinâmica da aula. Mais do que orientações ou breves comentários ao longo da aula, se caracteriza por uma parada que excede uma retrospectiva das atividades ou uma enumeração de nomes e referências:

\begin{abstract}
"Pra mim, em primeiro lugar, é um contar sobre o que estamos fazendo, sobre as funções das técnicas, por que elas estão sendo trabalhadas, o que pretendem atingir, qual é a função: em que podem mexer, o que podem provocar. É fundamental que as pessoas me contem se elas estão entendendo o que estão fazendo, se conseguem relacionar com a vida delas. Tudo tem a ver com a vida das pessoas, todos os exercícios e improvisações: com o organismo, com as relações, com o cotidiano. Eu tento provocar as pessoas a falar. É importante para a formação do ator que as pessoas aprendam a colocar as suas dúvidas por mais ingênuas que possam ser. Aprender a fazer perguntas idiotas é um processo de distribuir a racionalidade. É uma forma de expor sua alma, sua fraqueza, e se surpreender, você se surpreender, pois às vezes o ator começa a racionalizar demais e perde o primeiro ímpeto. A gente trabalha muito no curso com o primeiro ímpeto, a primeira sensação." (ZANATTA, 2010)
\end{abstract}

A hora do café acontece um pouco antes da metade da aula, normalmente após a segunda fase, no intervalo. A proposta vem sob influência da experiência de Zanatta na escola inglesa de Desmond Jones, onde a prática do lanche coletivo fazia parte. Lá, cada aluno contribuía semanalmente para o lanche. Apesar de já ter recebido a sugestão de cobrar pelo lanche, Zanatta acredita que existe além de uma função prática de alimentação (pois as pessoas vêm de suas atividades diárias e tem a necessidade de se alimentar antes da aula), e do aspecto de otimização de tempo (pois assim as pessoas não se demoram antes da aula lanchando, correndo o risco de perder o aquecimento), existe a questão do encontro. Existe um interesse no encontro 
entre as pessoas, por isso a característica de o lanche estar disponível sem restrições a todos. O cardápio se caracteriza pela informalidade e pela simplicidade: bolos e pães caseiros, nata, geléia, margarina, biscoitos, café e chá. Sobre isto Zanatta considera que:

\begin{abstract}
"é voltar um pouco pra infância. É um pouco do clown que é rústico, pois a origem dele é interiorana. Tem a ver com a tentativa de não pasteurizar, de não criar uma máquina de fazer alunos, mas fazer com que as pessoas se sintam em casa, se sintam à vontade. Que consigam enxergar estes outros elementos de simplicidade como um resgate, pois o que estamos fazendo basicamente no curso é resgatar da simplicidade." (ZANATTA, 2010)
\end{abstract}

Para Zanatta, trabalhar com atores e não-atores traz riqueza ao processo. Ele considera que a mistura de atores e não-atores é bem aceita por todos: "é como se fosse criado um terceiro viés. Existe outro caminho que não é nem o ator nem o não-ator, que é o de se relacionar. A gente está reaprendendo como se relacionar." (ZANATTA, 2010)

O trabalho com atores junto a não-atores é descrito por Zanatta pela seguinte parábola:

"Você lava seu carro e inicia a semana com o carro limpo. Você fica com a idéia que seu carro está limpo. Passa uma semana, duas semanas - e você ainda permanece com a idéia de que teu carro está limpo. Então você vai à casa de alguém e estaciona seu carro. E você vê que o carro do outro que está brilhando. Então você percebe: 'Nossa, meu carro está sujo! Acabei de lavar e ele está sujo!' Quando a gente mergulha num universo, é muito fácil se encerrar dentro desse universo e parar de perceber o que está acontecendo em volta dele. Vejo o universo do ator muito parecido com isso. $\mathrm{O}$ ator engessa facilmente quando ele começa a perder $\mathrm{O}$ contato com o mundo. Ele engessa técnicas, maneiras de representação, acaba não evoluindo. Quando ele pára de estudar ele não evolui. Ele pode ter até uma regressão no processo de 
atuação. Quando você coloca uma pessoa com o carro limpo - uma pessoa que não conhece as regras do teatro -, você começa a ter um confrontozinho desses de acordar. Faz com que o ator perceba que o carro dele está sujo. Ele começa a descobrir um pouco a dificuldade que ele tem de jogar. $O$ outro está jogando espontaneamente. Não tem regra nenhuma, está livre, solto. Como se faz teatro mesmo? Então esse 'estado bobo', esse estado espontâneo, acaba provocando o ator. Essa troca é muito viva, muito rica para o ator." (ZANATTA, 2010)

Zanatta também relata que durante os 15 anos de trabalho como professor tem convivido com essa experiência com atores profissionais. Destaca que alguns, inclusive, não conseguem, durante um processo de três meses, "desentalar" e sair de uma forma, uma "estrutura de ator" que criaram durante anos: "Alguns não conseguem mais sair daquilo, não conseguem se relacionar, brincar, jogar, improvisar. Existe um conceito de teatro, personagem, texto que não sai de suas cabeças, do racional do que é teatro." (ZANATTA, 2010). Zanatta considera este trabalho proposto pelo curso muito provocativo para o ator profi ssional.

Por outro lado, Zanatta também destaca que a convivência com alguns atores para quem nunca fez teatro, é muito provocativa. Evidentemente, destaca que nem todos os atores que procuram a escola tem a característica de estarem engessados.

"Tem alguns atores que se tocam rapidinho; com duas ou três semanas já estão jogando bem, por que eles têm o teatro, a base do teatro, uma finalização do teatro para jogar. Então estes atores começam a ser "guias" para as pessoas que estão começando a conhecer o teatro. E eles percebem que podem servir e se tornam garçons em cena. Eles dão apoio, eles puxam a pessoa pra brincar, pra jogar. Eles "servem de bandeja" a pessoa pra que ela possa jogar. E eles ao mesmo tempo vão se deliciando nesse servir, nesse apoio, nessa base que elas vão dando pro outro ator." (ZANATTA, 2010) 
Zanatta acredita que estes dois universos, o do ator e o do não-ator, se enriquecem juntos:

"O ator que conhece teatro se propõe a uma fantasia muito maior do que a pessoa que não conhece teatro ainda, por que ele sabe que o teatro é a permissão da fantasia. Quando ele abre o jogo, quando ele reconhece a possibilidade de brincar, jogar, improvisar, a fantasia dele vai longe. Então ele começa a fornecer elementos pra quem nunca fez teatro. E quem nunca fez teatro retorna com a espontaneidade, a brincadeira, o não saber, o não ter conceito nenhum, estar limpo, estar um pouco mais livre. Essa é a relação que se estabelece aqui no curso." (ZANATTA, 2010)

\section{ALGUMAS DEFINIÇÕES DE MAURO ZANATTA SOBRE O ENSINO DE TEATRO}

A seguir transcrevo uma parte da entrevista realizada com Mauro Zanatta, na Escola do Ator Cômico, em Curitiba, no dia 26 de fevereiro de 2010. A proposta das questões é de explorar o universo conceitual que norteia os trabalhos realizados na escola ${ }^{16}$.

Ismael Scheffler - O que é jogo?

Mauro Zanatta - Jogo é relacionamento, ou o tipo de relacionamento que acontece num momento. Toda vez que você, seja na improvisação livre, seja no clown, seja na montagem de um espetáculo, junta um grupo de atores, um grupo de atores com a platéia, um grupo de atores pra montar um espetáculo, vai se estabelecer uma relação. Esta relação é o jogo. Estamos dentro do mesmo jogo? Não estamos conseguindo jogar juntos? É conseguir entender

\footnotetext{
${ }^{16}$ Algumas das perguntas foram inspiradas em questões que a pesquisadora Josette Féral propõe a diversas pessoas de teatro, publicados em: Mise en scène et Jeu de l'acteur.
} 
que jogo é este em que estou entrando, que jogo é este que estou propondo. É "comprar" essa forma de relacionamento: vai comprar esta idéia ou vai querer jogar um jogo diferente, ficando dois jogos que não se entendem, que não se relacionam? O jogo passa a acontecer quando se estabelece o tipo de relacionamento. E o jogo incluiu também a platéia. Philippe Hottier dizia que não existe ator fora de seu tempo.

\section{I.S. - O jogo se ensina?}

M. Z. - O jogo se ensina. Se pode mostrar caminhos. Se pensar que a gente nasceu com certo grau de liberdade, de desejo de se relacionar com o mundo, de conhecer. A gente vai fechando as porteiras com a "adultização", com o processo de se sociabilizar. Na medida em que você começa a detectar para as pessoas, mostrar ou dar facilidade para que ela resgate essa pessoa livre e desejosa dentro dela, você começa a restabelecer com ela o jogo, começa a restabelecer as relações. Eu entendo o ensinamento do jogo como o restabelecimento de alguns elementos que as pessoas perderam durante 0 processo de sociabilização. À medida que você vai restabelecendo esses desejos, essas vontades, esse olhar pro mundo externo, esse contato com 0 que está acontecendo em volta de você, quando você tira esse estado embotado, trágico, e começa a restabelecer uma comunicação com o mundo, você está restabelecendo relação, está restabelecendo o jogo.

\section{S. - Como aumentar a disponibilidade do ator para o jogo?}

M. Z. - Eu trabalho a partir da brincadeira. Podemos ver, por exemplo, a criança como uma etapa da nossa vida na qual a gente joga muito com as pessoas, com os objetos, com o universo em volta. A idéia é tentar compreender que isto fez parte da nossa vida e que, de certa forma, faz parte ainda. A gente ainda tem a memória deste estado de brincadeira, de jogo, de relacionamento, de estar desprovido de tantos conceitos de mundo, de tantos posicionamentos e razões. Quando você percebe que conseguia jogar muito mais quando tinha menos razão, menos conceituação, sabia "um pouquinho menos" do que era a vida, você consegue restabelecer esse jogo na vida. Quando adulto a gente 
acaba, se não cuidar, criando outro estado, o de fingir que está brincando este talvez o mais perigoso. Fingir forçar o riso. No clown acontece muito isto. O ator entra em cena e ele, diretamente, vai em busca de provocar o riso da platéia sem estabelecer jogo nenhum, relação nenhuma. À medida que você vai restabelecendo essa relação consigo mesmo, com suas dificuldades, com sua tragédia, com a platéia que está à frente, com o ator que está ao seu lado, com certo grau de verdade pra você mesmo - não falo de verdade como conceito, como verdadeiro, mas da verdade de você com você mesmo - você vai ampliando o seu material. Aí, sim, eu acredito que o ator passa a ter a capacidade de "mentir", de fazer valer a "mentira", fazer valer o trabalho de ator, por que ele está buscando material próprio dele mesmo para poder convencer.

\section{S. - O que é improvisação?}

M. Z. - Improvisação, para mim, é um estado de sobrevivência. É você conseguir preencher lacunas. A nossa tendência, no estado adulto, é de planejar todos os caminhos. A tendência desse processo de "sociabilização mercadológica" é começar a se fechar muito, planejar muito a vida, planejar muito os encontros, se tornando praticamente um homem de negócios. Planejo o que eu vou falar, planejo a minha estratégia para trabalhar, os meus relacionamentos passam a ser estratégicos também: eu me envolvo, "putz, me apaixonei, tenho que falar, tenho que me declarar, tenho que...", e acaba tirando bastante o espaço da espontaneidade. O espaço de descobrir que jogo é esse que a gente vai jogar. A improvisação é esse olhar de sobrevivência. Eu venho com uma série de planos, mas me confronto com alguém que também tem uma série de planos. Acontece um conflito e sobra uma lacuna, um buraco, entre os dois. Vou ter que preencher este buraco para estabelecer uma relação. Se eu não preencher este buraco, a relação não acontece, o jogo não acontece. A improvisação é esta capacidade de flexibilizar os meus planos, as minhas propostas, as minhas razões, os meus conceitos. Flexibilizar para que eu consiga sobreviver aos encontros, aos relacionamentos. 


\section{S. - Improvisação se ensina?}

M. Z. - Na medida em que se resgata o jogo e a brincadeira, você vai entendo a improvisação também. Ela se ensina.

\section{S. - Como aumentar a disponibilidade do ator para a improvisação?}

M. Z. - Tem dois caminhos: um é fazer com que o ator entenda a improvisação - embora a palavra seja muito usada dentro do teatro (e fora do teatro, na sociedade ela é uma palavra bastante pejorativa: improvisar é fazer mal feito, é fazer uma coisa às pressas). Se você consegue restabelecer a potência da improvisação como uma atitude necessária à vida, à vida do ator e para os relacionamentos que ele está estabelecendo, você começa a fazer com que ele amplie essa capacidade de improvisar. Outro caminho, existe uma série de jogos que vão fazendo com que o ator agilize seu pensamento, racionalize menos, comece a usar outros elementos do seu corpo, comece a intuir, ouvir melhor, perceber o que está acontecendo, sentir as propostas que vem do colega, perder o medo de errar. Quando você começa a jogar você começa a perder o medo de errar. Você se permite mais. Você erra mais. Mas você também começa a acertar num grau maior. É um caminho que a partir do exercício você vai ampliando.

\section{S. - O que é teatro para você?}

M. Z. - Teatro é um recorte da vida que permite outros mergulhos. É um recorte onde a gente extrai da vida. O teatro é uma possibilidade de alcançar outros níveis de relacionamento e de trocar uma informação de forma festiva, um evento festivo com a platéia. É um ritual. Sai do cotidiano e estabelece outro momento: aqui se estancou esse ritmo cotidiano de vida e se estabelece um ritual, outro tipo de encontro. É um espaço muito interessante de se discutir a vida. É um local de muita intensidade. Talvez o teatro seja o momento em que a gente possa estar, pelo menos por um período, vivendo exatamente aquele momento. $\mathrm{Na}$ vida a gente busca amar verdadeiramente, odiar verdadeiramente. Mas tem sempre um freio. O amor é freiado, o ódio é freiado, o desejo de matar é freiado - por questões sociais, por estabelecimento de um 
jogo social. No palco você tem condições de viver intensamente estes estados emocionais e fazer com que pessoas consigam viver isso também com você. É uma grande viagem em grupo. Por isso que essa relação entre ator e diretor e artista e platéia é fundamental: você não está viajando sozinho, é um jogo.

\section{S. - Teatro se ensina?}

M. Z. - Teatro se ensina. Nem todo mundo aprende, mas se ensina. Nem todo mundo aprende por que é como qualquer coisa: depende de quem vem aprender, depende muito do desejo de aprender. Talvez este seja um elemento muito importante. Eu vejo cada vez mais que o que a gente tem que restabelecer nas pessoas é o desejo real de aprender, a verdadeira vontade de aprender. Não é essa propaganda: "eu estou aí para que me ensinem, por que talvez seja um grande caminho para mim”. Eu quero estar aqui mesmo? Eu quero aprender? Por que é que não falo? Por que é que não me exponho? Por que é que fico esperando que me digam tudo? Tem gente que vê que dá pra ir além dessa relação professor-aluno e consegue estabelecer um jogo de aprendizado real, enquanto outros ficam na expectativa e ficam passando por essa etapa de aprendizagem sem realmente levar nada, ou levam muito pouco.

\section{S. - Que se pode realmente ensinar ao ator?}

M. Z. - Eu vejo por etapas. A primeira etapa seria este trabalho que eu faço: resgatar o contato do ator com ele mesmo, esta afinidade. Eu sou uma pessoa normal, eu tenho amor, tenho ódio, me relaciono com uma sociedade que não é a que eu quero, mas eu também estou produzindo uma sociedade que não é perfeita. Restabelecer a pessoa, esse contato vivo dela com o mundo. A partir daí existem várias linguagens teatrais para trabalhar e o universo da literatura para mergulhar. Uma vez que você afina a sensibilidade da pessoa com o mundo externo e com ela mesma, você já deu um grande passo no ensinamento. A partir daí existe muita coisa. A literatura, a leitura é super fundamental, pois você já está trabalhando o imaginário deste ator. O trabalho físico é fundamental. Existem várias técnicas físicas para se trabalhar. Eu contesto algumas. Está se trabalhando em muitas novidades dentro do trabalho 
físico. Eu vim da linguagem da mímica corporal do Decroux, mas não tenho muita certeza se esse é o caminho pra trabalhar a fisicalidade do ator. Por isso também deixei a mímica meio de lado. Por que tenho dúvidas se ela liberta ou se ela aprisiona. Ao menos nesse etapa do Decroux. Talvez pós-Decroux muita gente tenha trabalhado no que ele estabeleceu e tenha desenvolvido uma seqüência que é mais libertadora. Ou, talvez, eu tenha aprendido-apreendido não inteiramente pela técnica do Decroux, mas pelo exercício do Marceau, onde a mímica era muito finalizada, muito para palco e acabava não sendo um exercício proposto pelo Decroux, e sim um projeto final de palco. Eu me senti inteiramente prisioneiro dela. O que o ator tem que aprender? É tudo: andar de bicicleta, pilotar uma moto, nadar, jogar basquete, ler, se relacionar com o filho. Tudo que diz respeito à vida diz respeito ao aprendizado do ator. Claro, quando você vai para o palco você pode pensar que a linguagem do palco não é a linguagem do cotidiano. Tem técnicas que você pode assimilar. Eu tenho abertura pra qualquer técnica, desde que ela não aprisione.

I. S. - Quais as técnicas básicas de fundamento do ofício que um ator deve possuir?

M. Z. - Improvisação. Compreensão de texto, leitura, literatura, dramaturgia. E a máscara, com todas as suas variações: desde o treinamento com a máscara neutra, a construção da commedia dell'arte, a linguagem física do butô... Esse triângulo dá, em minha opinião, muito "caldo". A gente teria uma base bem sustentada para $\mathrm{o}$ ator.

I. S. - Considera o talento como característica essencial ao ator?

M. Z. - Não essencial, mas um diferencial. Conheço atores que não são talentosos, mas que tem uma capacidade de trabalho e de dedicação que chegam a um nível muito bom de ator. No entanto, quem tem talento tem um diferencial.

\section{S. - O que é talento?}


M. Z. - Talento é uma espécie de genialidade, no sentido de que você percebe mais do que a média, ouve mais, tem um caminho de jogar muito maior, mais ampliado, com menos barreiras pra se relacionar com a criação. Não sei de onde vem. Pode estar relacionado com vários fatores, como foi seu contexto de criação, várias coisas que podem formar uma pessoa de talento. É uma inteligência, uma capacidade superior de lidar com a criação.

\section{S. - Teatro se aprende com os mais velhos, os mais experientes?}

M. Z. - Também. Não acho que exista uma idade pra você ter maturidade, pra você passar. Se você começar a se relacionar com uma pessoa de talento, ela pode ter 30 anos e ter muita coisa pra ensinar. Se você se relacionar com alguém que trabalhou muito arduamente, pesquisou muito, mas que não tem talento, talvez aos 70 esteja com uma maturidade para ensinar. Ou você pode pegar alguém que tem talento e que não trabalhou, que tem 70 , mas que está cheio de vícios, porque não conseguiu estabelecer relações e ficou só no talento e esse talento foi esmaecendo, e não vai ter muita coisa pra te ensinar também. Acho que o fundamental é o respeito do que é o trabalho de um ator mais velho.

\section{S. - Como se aprende teatro?}

M. Z. - Tem gente que não vai pra escola nenhuma. Tem muita gente fazendo faculdade. Tem muita gente que faz uma oficina de final de semana e daqui a pouco entra numa companhia e de repente é ator. O teatro é uma profissão assim: se aprende teatro estudando e compreendendo a vida. Tem algumas figuras que vão dizer claramente: "se eu preciso criar um louco, eu sei que o louco está dentro de mim. Existe um louco dentro de mim. Eu não preciso ir ao hospício pra aprender o que é loucura. Eu sou um ser humano que tem uma intensidade muito grande. Eu sou assim por que eu me sociabilizei, senão eu poderia ser um bicho ou um assassino cruel. Se eu tenho a capacidade de olhar para mim e saber o quão cruel, o quão animal eu posso ser, ou o quão bondoso e amoroso, e potente, o quão poderoso e fraco, ou um ninguém - se eu tiver essa capacidade de introspecção, de me revisar, de me reconhecer, eu 
já estou num processo de aprendizagem muito grande para o meu ator." $E$ tem escolas que também vão passar técnicas, linguagens, estudos de pessoas que fizeram teatro e que descobriram caminhos para se fazer teatro. Eu acredito nos dois caminhos. Me interessa muito este outro caminho, que é a de restabelecer o contato do ator com ele mesmo, com a pessoa dele. Isso me interessa muito, por que isto potencializa muito o ator. Eu digo que me interessa este, pois eu não tenho condições de desenvolver todos os caminhos. Este já é pra mim uma jornada muito grande. Já tenho muito material de pesquisa neste sentido.

\section{S. - No teatro, as pessoas precisam de mestres ou de professores?}

M. Z. - Precisam dos dois. Se elas pudessem ter um mestre que pudesse dar essa "mergulhada" psicológica, um mestre que desse uma conduzida na busca pessoal, seria bem importante. E aí ela pode ter professores para ensinar técnicas. Eu prefiro mestres, acho que é um avanço.

\section{S. - Qual a diferença entre um mestre e um professor?}

M. Z. - Mestre vai além da matéria, literalmente. Enquanto o professor faz o ator repetir um exercício, o mestre vai dar um pouco mais de sentido pra esse exercício, vai fazer uma conexão com o corpo do ator um pouco mais profunda. Talvez a gente tenha essa imagem de mestre meio que do kung fu, do zen. Mas isso não existe pra gente aqui. Maestria pra mim está muito ligada a uma prática, a uma maneira de enxergar a vida, de sair do pequeno, de estabelecer um espaço maior. Entender o teatro não só como o palco, o teu grupo de teatro. Teu grupo de teatro tem família, tem gente em volta, tem outros envolvimentos. A gente tem um trabalho que se chama teatro e esse trabalho tem que dar um retorno pra gente que seja uma forma de ver a vida diferente $\mathrm{e}$ viver a vida de uma maneira diferente. Se não tiver este retorno, se eu ficar só no "teatro" e não conseguir ter esse retorno pra minha vida, eu estou no "professor". Se eu conseguir ir ao teatro e voltar pra minha vida diferente, eu estou num estado da maestria. A maestria a gente pode encontrar em vários lugares, inclusive onde não existe uma tentativa clara de se ser mestre. 


\section{S. - Você teve mestres?}

M. Z. - Eu acredito que tenha tido algumas figuras com grau de maestria, mas com contato muito pequeno que não chegou a se estabelecer. Mas eu entendi um pouco do processo. Eles me ensinaram muito em pouco tempo. Com mestres, em pouco tempo de contato eu aprendi muito. Eles desencadearam, mexendo naquela "chavezinha" que estava precisando ser mexida em mim. Me deram o toque que eu estava precisando. Philippe Hottier foi um, apesar do pouco contato com ele.

\section{S. - Você é mestre ou professor?}

M. Z. - Eu procuro a maestria. Procuro o trabalho do mestre. Não me interessa só ensinar teatro. Me interessa criar vínculos. Estabelecer uma relação do teatro com a sociedade que a gente vive, com as pessoas. Me interessa usar o teatro como um caminho de entender por que a gente esta fazendo as coisas, como a gente pode viver melhor, como a gente pode criar novas relações. Não ficar voltados e fechados num grupo. Eu me estabeleço num grupo para que ele me ajude a estabelecer relações externas e não pra criar um dogma: "é assim que se faz teatro", "é assim que 'a gente' faz teatro'.

\section{CONSIDERAÇÕES FINAIS}

A Escola do Ator Cômico trouxe a Curitiba um modelo diferenciado de formação do ator e tornou-se referencial por propor uma abordagem por meio da comédia. Além disto, possui uma proposta de trabalho que envolve indistintamente diferentes públicos: atores profissionais, pessoas com aspiração à carreira profissional e pessoas em busca de um espaço de desenvolvimento pessoal por meio do teatro.

O fato de a escola ser procurada por grande número de atores profissionais demonstra sua relevância e o reconhecimento de um ensino 
diferenciado e próprio. Se inicialmente o que atraía este público eram linguagens teatrais específicas e técnicas corporais, atualmente, embora a ênfase da escola tenha mudado, persiste a grande afluência de atores profissionais em busca pelo desenvolvimento da improvisação, do jogo e da comédia. Nas palavras do próprio Zanatta, o objetivo da Escola do Ator Cômico é de "preparar o ator por meio de técnicas de comédia para o teatro, propiciando um enfrentamento pessoal, capaz de fazêlo retornar às suas bases para um reencontro com o seu verdadeiro potencial." (ZANATTA, 2010)

Não obstante este perfil de aluno, a escola desperta e encaminha à carreira outro número de "não-atores" que se descobrem atores, sendo a escola, portanto, responsável pela formação e iniciação de novos profissionais.

A Escola do Ator Cômico possui uma proposta pedagógica bastante clara, calcada em princípios sempre de novo revistos e aprimorados. Diferentemente de uma proposta de ensino tecnicista, Zanatta entende o ator como um ser global, no qual as fronteiras entre vida e arte se estreitam, ou, ainda, não se distinguem. O ator é um ser humano. Trabalhar o ator é trabalhar o ser humano. Indo além de um ensino de técnicas ou informações históricas e teóricas, Zanatta pretende conduzir o aluno a um mergulho interior, mas, como ele mesmo destaca, não se propõe à realização de um trabalho terapêutico. Ele visualiza em estudos da Psicomotricidade Relacional e da psicologia corporal reichiana possibilidades para o ator. Interesses que aparecem desde cedo em sua trajetória e vão se afirmando de diferentes formas investigativas, como na parceria realizada com a terapeuta corporal Arnand Djarna, em 1999, e sua formação reichiana recente.

Tendo como medida sua vivência como ator, Zanatta parece construir uma proposta de ensino motivado por seus próprios conflitos profissionais. Daí a afirmar a necessidade de estar em cena constantemente, testando, sentindo, revisando e assumindo-se como cobaia de seus princípios.

Tudo isto também ajuda a compreender o fato de a escola possuir atualmente um único professor. A Escola do Ator Cômico possui uma procura maior de alunos do que atende todos os anos, mas Zanatta não demonstra a visão empreendedora de contratação de outros professores como uma alternativa para ampliar os negócios. Centrada numa proposta muito pessoal e 
em constante refinamento, Zanatta parece resistir ao imaginário de ser a escola "uma máquina de fazer atores", aproximando-se, embora não afirmado por ele, de um processo que se estenda para além da docência em direção à maestria.

Por fim, é importante destacar a visão de Zanatta de que o trabalho desenvolvido no atual Curso de Comédia para Atores e Não-atores corresponde simplesmente a uma parte do processo na formação do ator, pois ele mesmo aponta outras áreas que considera fundamentais para a formação do ator, assumindo, ele, apenas uma parte deste trajeto.

Todos estes aspectos atribuem à Escola do Ator Cômico um caráter diferenciado no âmbito paranaense e nacional, como um espaço que há 15 anos contribui para a formação do ator.

\section{REFERÊNCIAS BIBLIOGRÁFICAS}

BORBA, Patricia de. Entrevista com Pita Belli sobre a Escola do Ator Cômico - por e-mail. 19 de fevereiro de 2010.

CENTRO Cultural Teatro Guaíra. Website: <http://www.tguaira.pr.gov.br/> Acesso em: 16 de janeiro de 2010.

ESCOLA do Ator Cômico. Website: <http://www.atorcomico.com.br> Acesso em: 15 de jan 2010.

FÉRAL, Josette. Mise en scène et Jeu de l'acteur. Tome 2: Le corps en scène. Montréal (Québec)/Carnières (Morlanwelz): Jeu/Lansman, 2001.

MASTEY, Raquel. Entrevista com Raquel Mastey sobre o curso de teatro do Colégio Estadual do Paraná e o ensino de cenografia para o autor por e-mail. 19 de junho de 2009.

TEIXEIRA, Selma Suely. Amadores em cena 2: o Teatro de Adultos e a Escola de Arte Dramática do SESI. Niterói : Bacantes, 2001. 
ZANATTA, Mauro. Entrevista concedida ao autor na Escola do Ator Cômico. 213 min. 3 partes. Curitiba: 29 janeiro e 27 fevereiro de 2010. 